\title{
Clearing a roadmap
}

he National Institutes of Health Roadmap was unveiled last September (1) and has created a mix of interest, concern, and confusion in the scientific community. Much of the concern and confusion relates to the uncertainty of how the Roadmap initiatives will impact a researcher's abil-

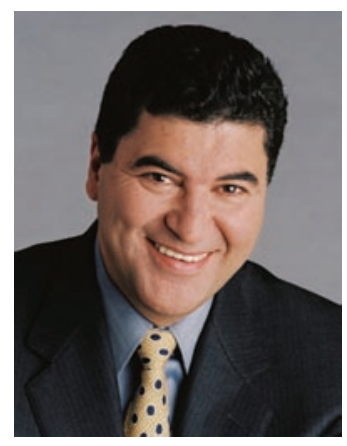

Elias Zerhouni: "We need transforming strategies that are orders of magnitude greater in effectiveness than what we have today."

ity to be funded if his or her work is not directly related to the missions highlighted in the initiatives. NIH Director Elias Zerhouni underscored these concerns in his presentation April 20 at Experimental Biology, "Will You Still Fund Me Tomorrow? The Deficit, Biodefense, and the NIH Roadmap." He told the audience, "These initiatives are not top down; they are investigator initiated."

In discussions after the talk, one researcher commented, "I was under the impression that I should not bother writing my next R01 ... and that is not the message I got here."

So - at least for this meeting - mission accomplished. Since September, Zerhouni and various divisional directors from individual institutes have gone on a roadshow to numerous meetings to present and re-present the objectives of the Roadmap, to clarify their importance, and to calm any fears.

At Experimental Biology, Zerhouni repeatedly stated that the work was investigator initiated, was not top-down research, and was not large-scale science.

Zerhouni said he had heard many people say, "this roadmap is in competition with everything else. It will reduce the number of R01s, and my chance of getting a grant is going to be completely destroyed by this large-scale science program." He assured the audience that "nothing could be farther from the truth. The program, first of all, is not large-scale science; it's not the human genome. What it is, is a collection of initiatives that are very focused on those scientific areas that were identified as potential roadblocks that needed to be stimulated across these areas."

The Roadmap has been in development since mid-2002. The details of that process and the strategies developed are provided at http://nihroadmap.nih.gov. At its core, the Roadmap is made up of three primary themes: (a) new pathways to discovery, (b) research teams of the future, and (c) re-engineering the clinical research enterprise.

The strategies designed to address these themes were developed through several meetings with more than 300 individuals from outside the NIH. Dushanka Kleinman, the recently appointed assistant director for Roadmap coordination, told the JCI, "The individuals who were brought in to provide advice to the NIH and to [the] director regarding the Roadmap were first identified by the institute and center directors as individuals who had a broad vision, experience, and were active in a research field that would enable them to address the key questions that were put forth on the Roadmap, such as identifying what the roadblocks are for scientific opportunities and progress, what some of the proposed solutions are, and what recommendations there are to an agency such as the NIH for acting on and addressing the roadblocks as they were perceived."

Christopher Austin is senior advisor for translational genomics research and the head of one of the new high-throughput screening centers that are being developed as one of the initiatives under the Roadmap theme of "new pathways to discovery." He felt that an error of commission and an error of omission had been made during the initial presentation of the Roadmap initiatives. "The error of commission," he said, "was to present the Roadmap initiatives in only these sort of grand terms" that primarily highlighted the processes of multidisciplinary activities and new resource centers. "The error of omission was to leave out the fact that the vast majority, in terms of what percentage of the Roadmap will go through these big central grants and what part will go through the normal process, will be the normal process."

The Roadmap initiatives are taking up only a small portion of the NIH budget: approximately $1 \%$ each year. In 2004, this is approximately $\$ 128$ million, and

\section{"So if anybody tells me that the $0.9 \%$ of the NIH budget is going to have a huge impact, they have not looked at the data."}

in 2005, the proposed amount is $\$ 237$ million. In past years, when the NIH was seeing a doubling of their budget, such a minor addition might have meant very little in terms of its impact on other grants, but in a year when there was only a $3.1 \%$ increase in the NIH budget, compared with last year's increase of $16.6 \%$, the research community is concerned about the impact these initiatives will have on other grants.

Zerhouni shared his feelings about this in his presentation at the meeting. "When you look at the totality of these investments," he said, "it is $\$ 128$ [million] in '04, \$237 [million] in '05. Then we stay at

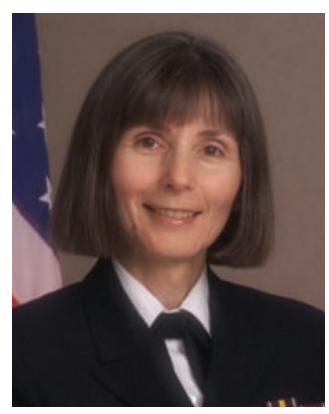

Dushanka Kleinman: "We have seen a very positive response through the large number of RM grant submissions." 
about $1-1.2 \%$ of the NIH budget for about 2 years, and then we go back down again. The total amount is about $\$ 2.1$ billion in the same period of time that, using the most conservative of growth estimates, the NIH will have received $\$ 220$ billion in budget. So if anybody tells me that the $0.9 \%$ of the NIH budget is going to have a huge impact, they have not looked at the data. The data do not support this sort of statement that I have heard from many people who are concerned."

The money for this $1 \%$ comes from two places within the NIH. One is the NIH director's discretionary funds.

Kleinman told the JCI that "in this fiscal year, '04, of the total \$128 million, $\$ 35$ million comes from the director's discretionary funds. And in '05, \$60 million of the projected $\$ 237$ million comes from the director's discretionary funds." The total amount of the discretionary funds, Kleinman said, "varies from year to year, but, for example, in '04 it was \$45 million, and in '05 it's $\$ 70$ million." So approximately $78 \%$ of the discretionary funds in 2004, and about $85 \%$ in 2005 , are going into the new initiatives.

The remainder of the money for the new initiatives is to come from the institutes, each of which might then reduce its individual pool for competing and new grants. While the Roadmap money that comes from the institutes is clearly a very small amount relative to the total

"When the doubling came,"
Zerhouni explained, "we
invested more money on
the same grants, and then
we invested money on new
grants."

NIH budget, at a time when many fear that past large budgetary increases have created a backlog of grants in need of renewal, with increases expected annually, it might make the funding of new grants that much more difficult.

In his presentation, Zerhouni showed that during the time of budget doubling, the number of grants actually rose by only $40 \%$. This was because the funding amounts of grants also rose, by $45 \%$, during the same period.
"When the doubling came," he explained, "we invested more money on the same grants, and then we invested money on new grants."

Zerhouni made it clear that for the future, the most important goal is to

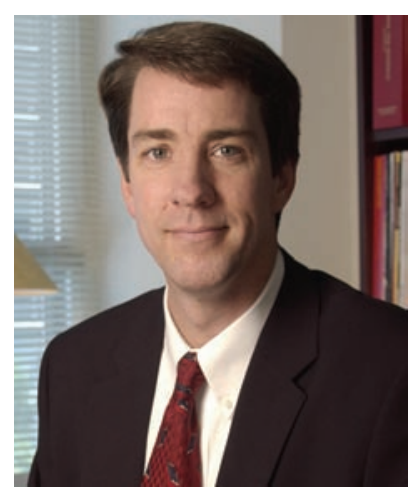

Christopher Austin: "These initiatives will put different sorts of tools into researchers' hands."

continue to fund as many new grants as possible within the limits of tight budgetary restrictions. "All of our budget strategies," he told the audience, "have been to minimize the impact on the number of grants available for researchers. We would rather make cost increases by $1 \%$ so that we can increase the number of competing grants.

"This is a hard choice. We don't feel we should fall too far below inflation, but we would rather encourage investigators, and young investigators in particular. Our strategy is to fund more grants. We want to preserve the ability for our investigators to stay in the game of research."

It is predicted that approximately $27 \%$ of grants will be funded in ' 04 and ' 05 . This is about $3 \%$ lower than that seen during the doubling of the budget, but a far cry higher than the funding rate of $14-16 \%$ seen in the 1980 s, a time during which Zerhouni recalled that many young scientists, himself included, were discouraged by the limited opportunities available in research.

At the end of the session, it was clear that the concerns of many members of the audience had been eased. One researcher even stood up and admitted, "I was surprised to learn today that only $1 \%$ of the NIH budget was committed to the Roadmap." Then he added, "But since it is so small, how committed are you to these new initiatives?”

Zerhouni laughed, perhaps realizing the irony that in alleviating concerns for the new initiatives taking up too much grant money, he had opened the door to an opposing group of concerns. "Here's the strategy. When you have a portfolio of research, you need a component of the portfolio to include a risk area. As with a stock portfolio, you should have a good portion of your investment in solid bonds and conservative companies, but some small portion in the venture capitalist regions. This can be used to stimulate out-of-the-box thinking, even in the main portfolio. But, if you took $20 \%$ of the NIH budget, you would be an imprudent advisor."

The NIH will not, however, be waiting five years to see whether these initiatives do turn out to be a well-managed research portfolio. Kleinman told the JCI, "We're developing an overall Roadmap evaluation scheme. And we will be monitoring it very closely. There is a Roadmap implementation coordination committee that is comprised of the chairs of the different working groups and representatives of the office of the director. We are watching closely as this unfolds and clearly are interested in only meritorious research.”

The research community will likewise be watching closely.

\section{Laurie Goodman}

1. Zerhouni, E. 2003. The NIH Roadmap. Science. 302:63-64, 72 . 